\title{
Atenção à saúde de homens e mulheres transexuais brasileiras: uma evidência de pesquisa
}

Health care for brazilian transexual men and women: an evidence of research

Atención de salud para hombres y mujeres transexuales brasileños: una prueba de investigación

\begin{abstract}
RESUMO
Introdução: A transexualidade se caracteriza pelo reconhecimento da pessoa ao gênero diferente do seu nascimento. Quando essa não consegue se perceber e conviver saudavelmente com o seu corpo biológico, inúmeras podem ser as repercussões geradas em sua vida, reproduzidas, quase sempre, pelo preconceito da sociedade. Objetivo: descrever as evidências de pesquisa sobre a atenção à saúde de homens e mulheres transexuais. Metodologia: Revisão integrativa da literatura, nas bases de dados LILACS, BDENF e MEDLINE, com artigos no idioma português, publicados entre 2009 a 2019. Resultados: Foram encontrados 284 estudos, sendo 06 incluídos para a análise. Conclusão: A promoção da saúde apresentou-se como fundamental para homens e mulheres transexuais, isso porque melhora a inclusão social, favorece o vínculo, a conquista da autonomia, da autoestima e do autocuidado. Colocá-la em prática requer dos profissionais de saúde um olhar centrado na pessoa, não no seu corpo, seu gênero e sua sexualidade.
\end{abstract}

DESCRITORES: Transexualismo; Assistência à Saúde; Revisão.

\section{ABSTRACT}

Introduction: Transsexuality is characterized by the recognition of the person to a different gender from his birth. When it fails to perceive itself and live healthily with its biological body, there can be countless repercussions generated in its life, reproduced, almost always, by society's prejudice. Objective: to describe research evidence on health care for transsexual men and women. Methodology: Integrative literature review, in the LILACS, BDENF and MEDLINE databases, with articles in Portuguese, published between 2009 and 2019. Results: 284 studies were found, 06 of which were included for analysis. Conclusion: Health promotion was presented as fundamental for transsexual men and women, because it improves social inclusion, favors the bond, the achievement of autonomy, self-esteem, and self-care. Putting it into practice requires health professionals to focus on the person, not on their body, gender, and sexuality.

DESCRIPTORS: Transsexualism; Health Care; Review.

\section{RESUMEN}

Introducción: La transexualidad se caracteriza por el reconocimiento de la persona a un género diferente al de su nacimiento. Cuando no se percibe y convive sanamente con su cuerpo biológico, pueden generarse innumerables repercusiones en su vida, reproducidas, casi siempre, por los prejuicios de la sociedad. Objetivo: describir la evidencia de la investigación sobre la atención de la salud de hombres y mujeres transexuales. Metodología: Revisión integrativa de la literatura, en las bases de datos LILACS, BDENF y MEDLINE, con artículos en lengua portuguesa, publicados entre 2009 y 2019. Resultados: Se encontraron 284 estudios, 06 de los cuales fueron incluidos para análisis. Conclusión: La promoción de la salud se presentó como fundamental para hombres y mujeres transexuales, porque mejora la inclusión social, favorece el vínculo, el logro de la autonomía, la autoestima y el autocuidado. Ponerlo en práctica requiere que los profesionales de la salud se concentren en la persona, no en su cuerpo, género y sexualidad.

DESCRIPTORES: Transexualismo; Asistencia Sanitaria; Revisión.

RECEBIDO EM: 15/08/2020 APROVADO EM: 25/08/2020

\section{Sabrina do Nascimento Moreira}

Graduada pela Associação Brasileira de Ensino Universitário (UNIABEU).

ORCID: 


\title{
Fernanda Viera Paz
}

Enfermeira. Graduada pelo Centro Universitário UNIABEU.

ORCID:

\author{
Albert Lengruber de Azevedo \\ Doutor e Mestre em enfermagem pela Escola de Enfermagem Anna Nery. Professor do Centro universitário Belford Roxo e da \\ Faculdade Duque de Caxias, RJ - Brasil. \\ ORCID:
}

Keila do Carmo Neves

Enfermeira. Doutora e Mestre em Enfermagem pela Escola de Enfermagem Anna Nery, da Universidade Federal do Rio de Janeiro (EEAN/UFRJ).

ORCID:

\section{Alessandra Januário Giesteira}

Mestre em saúde materno infantil. Especialista em saúde da mulher e em Saúde da família. Docente - UNIABEU. ORCID:

\section{Taiana Daniella Pereira de Azevedo}

Enfermeira. Especialista em Controle de Infecção em Assistência à Saúde. Docente UNIABEU. ORCID:

\section{Elaine Cristina Rodrigues da Costa}

Enfermeira pela PUCPR, Mestre Tecnologia em saúde pela PUCPR. especializando em ESF- UFF. Docente UNIABEU. Supervisora de estágio em clínica da família.

ORCID:

\section{INTRODUÇÃO}

$\square$ ste estudo buscou explorar o seguinte objeto de estudo: a atenção à saúde para homens e mulheres transexuais.

A transexualidade é um fenômeno não tão novo na área da saúde brasileira, que se caracteriza pelo reconhecimento da pessoa ao gênero diferente do seu nascimento. Nele, tanto o homem quanto a mulher tendem a desenvolver uma "luta" "interna" e "externa", constantemente, contra as alterações que passam a acontecer com o seu corpo, nisso, o aumento abdominal, o estiramento do quadril, o crescimento de pelos, das unhas e, também dos $\operatorname{seios}^{(1)}$.

Quando essa pessoa não consegue se perceber e conviver saudavelmente com o seu corpo biológico, inúmeras podem ser as repercussões geradas em sua vida, quase sempre reproduzidas pelo preconceito da sociedade. E isso, muitas das vezes, faz com que ela se coloque na condição de vulnerável, como alguém que nasceu em um corpo diferente, com urgência para corrigi-lo $^{(2)}$.
O transexual representa, nesse contexto, uma clientela normal como qualquer outra, com condições de saúde iguais, portanto, não detentora de uma doença mental ou de uma depravação sexual. E, para melhorar o seu acesso aos serviços de saúde, bem como incentivá-la ao autocuidado, o enfermeiro precisa atentar-se à própria postura adotada, antes mesmo de se colocar disponível para escutá-la, sobretudo, para não agir com discriminação e influenciar negativamente na sua saúde biológica, física, psíquica e emocional ${ }^{(3)}$.

Decidiu-se explorar esse assunto em profundidade por se tratar de uma problemática importante para a formação de futuros enfermeiros, uma vez que a atenção à saúde, seja de homens ou de mulheres, ainda se encontra sustentada em uma lógica heteronormativa presumida, ou seja, constantemente marcada pela dificuldade em se criar vínculos sociais ${ }^{(4)}$.

Além disso, carece de uma premente atualização e sensibilização de profissionais de saúde, principalmente no que diz respeito à compreensão da identidade de gênero (feminino e masculino), processo de modificação corporal, uso de roupas, troca de nome, consumo diário de medicamentos como os hormônios e, realização de cirurgias para a mudança de sexo, todos assegurados pelo Sistema Único de Saúde - SUS ${ }^{(5)}$.

E, ao considerar tudo o que se contextualiza, ficou definido o seguinte objetivo: descrever as evidências de pesquisa sobre a atenção à saúde de homens e mulheres transexuais.

\section{METODOLOGIA}

Essa é uma pesquisa de revisão integrativa de literatura, considerada importante nas ciências da saúde pelas suas ricas contribuições, que envolvem desde a construção do conhecimento, à produção de saber fundamentado e uniforme e realização de uma prática assistencial com qualidade. Além disso, esse é um método que reduz os obstáculos para a utilização do conhecimento, uma vez que em um único estudo o leitor tem acesso a diversas pesquisas. E, ao se fundamentar 
em seis etapas sistemáticas, torna os resultados de pesquisas mais acessíveis ${ }^{(6)}$.

Primeira etapa: identificação do tema e seleção da hipótese ou questões de pesquisa para elaboração da revisão integrativa. Sustenta-se a partir das informações obtidas anteriormente sobre a temática, que permitiram formular uma pergunta de pesquisa, a saber: Como se dá a atenção à saúde de homens e mulheres transexuais?

Segunda etapa: estabelecimento de critérios para inclusão e exclusão de estudos/ amostragem ou busca na literatura. Subsequente definiram-se os seguintes critérios de inclusão: artigos completos, no idioma português, publicados entre 2009 e 2019 , que abordassem a temática da atenção à saúde de homens e mulheres transexuais. Exclusão: os estudos que se apresentavam com duplicidade nas bases de dados, disponíveis apenas como teses, dissertações, manuais, resumos, cartas ou editoriais.

Terceira etapa: definição das informações a serem extraídas/selecionadas/ categorizadas. As bases de dados selecionadas para acesso eletrônico foram: LILACS (Literatura Latino-Americana e do Caribe em Ciências da Saúde), Banco de Dados da Enfermagem (BDENF) e Medical Literature Analysis and Retrieval System Online (MEDLINE), todas da Biblioteca Virtual em Saúde, justificadas pela sua gratuidade.

Os descritores empregados para a obtenção de informações foram "Transexualismo" e "Assistência à saúde". Optou-se pela sua utilização, porque após combinados, permitiram encontrar um número significativo de estudos sobre a atenção à saúde de homens e mulheres transexuais. O operador booleano "and" foi definido como estratégia, por ajudar a refinar a busca por evidências de pesquisa. E, no que diz respeito a essas informações, foram consideradas pertinentes aquelas cujo objeto de estudo relacionava-se à temática proposta, respectivamente.

Quarta etapa: avaliação dos artigos incluídos na revisão integrativa. Nessa etapa, foram percorridos quatro momentos de produção de dados. Primeiro momento: os artigos encontrados foram revisados para identificação de duplicadas. Segundo momento: dois revisores responsabilizaram-se por analisar os títulos e resumo dos artigos e remover aqueles que não estavam disponíveis para acesso na íntegra. Terceiro momento: os revisores realizaram a leitura dos artigos na íntegra, excluindo-se aqueles que não respondiam à questão de pesquisa. Quarto momento: os artigos foram lidos integralmente, elegendo-se aqueles que apresentaram relação com o objeto definido para esse estudo.

Quinta etapa: interpretação dos resultados. Os artigos obtidos foram analisados por ambas as discentes, que se atentaram à comparação do conhecimento teórico, identificação de conclusões, e possíveis implicações dos resultados para a sua avaliação crítica. Todos eles foram lidos na sua íntegra, considerando-se a abrangência do seu conteúdo. Dessa etapa, foi extraído o máximo de informações

Figura 1. Fluxograma dos manuscritos selecionados e incluídos para a análise, considerando as bases de dados LILACS, BDENF e MEDLINE. Rio de Janeiro, RJ, Brasil, 2019.

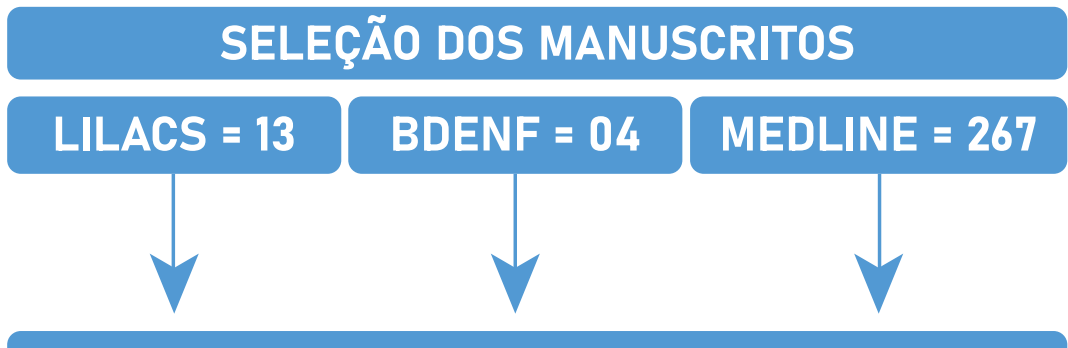

TOTAL DE ARTIGOS SELECIONADOS 284

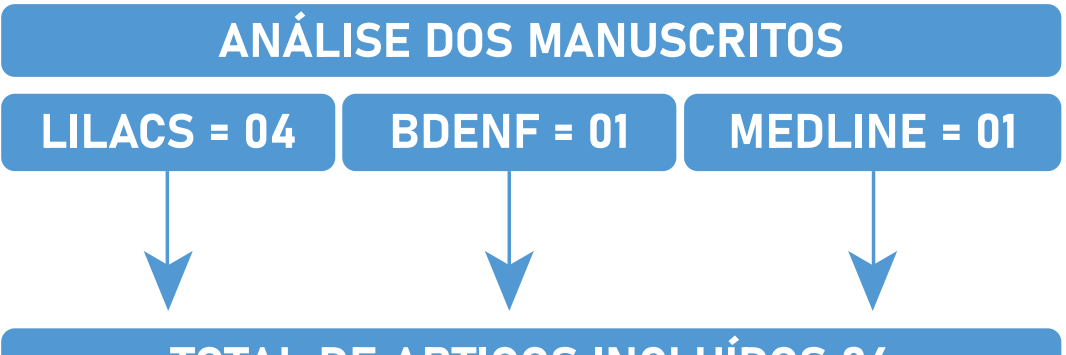

TOTAL DE ARTIGOS INCLUIDOS 06 


\section{artigo}

Moreira, S.N.; Paz, F.V.; Azevedo, A.L.; Neves, K.C.; Giesteira, A.J.; Azevedo, T.D.P.; Costa, E.C.R.

Atenção à saúde de homens e mulheres transexuais brasileiras: uma evidência de pesquisa

Posteriormente, deu-se à caracterização dos artigos encontrados nas bases de dados, seguida da descrição de algumas de suas informações, como: o título, os anos, os objetivos, o método, os resultados, a conclusão, e os modos de atenção à saúde, conforme apresentado no quadro a seguir.

Após essa etapa, ficou evidenciado que a promoção da saúde se apresenta

Quadro 1. Caracterização dos artigos: base de dados, título, ano, objetivos, métodos, resultados, conclusão, e formas de atenção à saúde. Rio de Janeiro, RJ, Brasil, 2019

\begin{tabular}{|c|c|c|c|c|c|c|}
\hline $\begin{array}{l}\text { BASE DE } \\
\text { DADOS }\end{array}$ & TÍTULO / ANO & OBJETIVOS & MÉTODOS & RESULTADOS & CONCLUSÃO & $\begin{array}{l}\text { MODELOS DE } \\
\text { ATENÇÃO Ã } \\
\text { SAUUDE }\end{array}$ \\
\hline LILACS & $\begin{array}{c}\text { Atenção integral } \\
\text { à saúde e diver- } \\
\text { sidade sexual no } \\
\text { Processo Tran- } \\
\text { sexualizador do } \\
\text { SUS: avanços, } \\
\text { impasses, } \\
\text { desafios. } \\
2009\end{array}$ & $\begin{array}{c}\text { Analisar criticamente } \\
\text { os avanços, impasses e } \\
\text { desafios na instituição } \\
\text { de políticas públicas de } \\
\text { saúde voltadas para o } \\
\text { Processo Transexuali- } \\
\text { zador, e discutir a ambi- } \\
\text { valência desse processo } \\
\text { de construção de uma } \\
\text { norma técnica. }\end{array}$ & Qualitativo & $\begin{array}{l}\text { Evidencia e denuncia } \\
\text { a complexidade do } \\
\text { avanço dos direitos } \\
\text { sexuais no campo da } \\
\text { saúde coletiva. }\end{array}$ & $\begin{array}{l}\text { Como são os desa- } \\
\text { fios que as pessoas } \\
\text { transexuais enfren- } \\
\text { tam a respeito da sua } \\
\text { saúde. }\end{array}$ & $\begin{array}{l}\text { Promoção da } \\
\text { saúde. } \\
\text { Resgate dos } \\
\text { princípios da } \\
\text { universalidade, } \\
\text { integralidade e } \\
\text { equidade. }\end{array}$ \\
\hline LILACS & $\begin{array}{l}\text { Do diagnóstico } \\
\text { de transtorno } \\
\text { de identidade } \\
\text { de gênero às } \\
\text { redescrições da } \\
\text { experiência da } \\
\text { transexualidade: } \\
\text { uma reflexão } \\
\text { sobre gênero, } \\
\text { tecnologia e } \\
\text { saúde. } \\
2009\end{array}$ & $\begin{array}{c}\text { Analisar os avanços da } \\
\text { tecnologia médica e da } \\
\text { influência da revolução } \\
\text { dos costumes na } \\
\text { problematização da } \\
\text { imutabilidade do sexo } \\
\text { e da categoria de } \\
\text { gênero; e compreender } \\
\text { o motivo pelo qual } \\
\text { a regulamentação } \\
\text { do acesso à saúde } \\
\text { para a modificação } \\
\text { das características } \\
\text { corporais do sexo } \\
\text { ficou associada à } \\
\text { definição da condição } \\
\text { transexual. }\end{array}$ & Qualitativo & $\begin{array}{l}\text { Trouxe esclarecimento } \\
\text { a respeito de gênero, } \\
\text { sexualidade tecnolo- } \\
\text { gias e saúde. }\end{array}$ & $\begin{array}{l}\text { A assistência ao } \\
\text { transexual no Brasil } \\
\text { se mostra ainda, } \\
\text { frágil e ineficiente } \\
\text { por não conseguir } \\
\text { alcançar de maneira } \\
\text { efetiva o indivíduo } \\
\text { em todas as suas } \\
\text { necessidades. }\end{array}$ & $\begin{array}{l}\text { Promoção da } \\
\text { saúde. }\end{array}$ \\
\hline LILACS & $\begin{array}{c}\text { Limites e } \\
\text { possibilidades } \\
\text { do exercício } \\
\text { da autonomia } \\
\text { nas práticas } \\
\text { terapêuticas } \\
\text { de modifica- } \\
\text { ção corporal } \\
\text { e alteração } \\
\text { da identidade } \\
\text { sexual. } \\
2009\end{array}$ & $\begin{array}{c}\text { Discutir o conflito } \\
\text { moral entre o sujeito } \\
\text { transexual e as normas } \\
\text { vigentes em relação ao } \\
\text { exercício da autonomia } \\
\text { individual nas práticas } \\
\text { terapêuticas; e aplicar } \\
\text { as ferramentas da bio- } \\
\text { ética, a partir da análise } \\
\text { dos argumentos utiliza- } \\
\text { dos pelas instâncias de } \\
\text { saúde e judicial sobre } \\
\text { o tema, nos artigos, } \\
\text { documentos e decisões } \\
\text { judiciais nacionais. }\end{array}$ & Qualitativo & $\begin{array}{l}\text { Evidenciou-se que } \\
\text { o direito da pessoa } \\
\text { transexual à assistên- } \\
\text { cia à saúde precisa ser } \\
\text { integral, inclusive a } \\
\text { sexual, que é infringida } \\
\text { pela não preservação } \\
\text { da sua autonomia. }\end{array}$ & $\begin{array}{c}\text { Obtiveram-se avan- } \\
\text { ços no acesso aos re- } \\
\text { cursos terapêuticos } \\
\text { e legais, porém as li- } \\
\text { mitações e restrições } \\
\text { impostas ao exercício } \\
\text { da sua autonomia } \\
\text { podem gerar efeitos } \\
\text { negativos para sua } \\
\text { saúde. }\end{array}$ & $\begin{array}{l}\text { Promoção da } \\
\text { saúde. }\end{array}$ \\
\hline
\end{tabular}




\begin{tabular}{|c|c|c|c|c|c|c|}
\hline LILACS & $\begin{array}{l}\text { (Trans)forma- } \\
\text { ções corporais: } \\
\text { reflexões sobre } \\
\text { saúde e beleza. } \\
2017\end{array}$ & $\begin{array}{l}\text { Acompanhar as trans- } \\
\text { formações corpóreas } \\
\text { empreendidas por pes- } \\
\text { soas trans, analisando } \\
\text { as dimensões materiais } \\
\text { e imateriais envolvidas } \\
\text { nesse processo e os } \\
\text { sentidos de beleza, saú- } \\
\text { de e doença em deriva } \\
\text { nessas experiências. }\end{array}$ & Qualitativa & $\begin{array}{c}\text { Evidenciou-se uma } \\
\text { importante divergência } \\
\text { entre as compreensões } \\
\text { de saúde e doença pro- } \\
\text { duzida pelos poderes } \\
\text { e saberes biomédicos } \\
\text { sobre os corpos trans, e } \\
\text { aquelas que as pessoas } \\
\text { trans produzem sobre } \\
\text { si mesma. }\end{array}$ & $\begin{array}{l}\text { O respeito à auto- } \\
\text { nomia das pessoas } \\
\text { trans e a mudanças } \\
\text { nos seus corpos pro- } \\
\text { movendo a promo- } \\
\text { ção em saúde. }\end{array}$ & $\begin{array}{l}\text { Promoção da } \\
\text { saúde. }\end{array}$ \\
\hline BDENF & $\begin{array}{c}\text { A medicalização } \\
\text { e patologização } \\
\text { na perspectiva } \\
\text { das mulheres } \\
\text { transexuais: } \\
\text { acessibilidade } \\
\text { ou exclusão } \\
\text { social. } \\
2017\end{array}$ & $\begin{array}{l}\text { Descrever a percepção } \\
\text { das mulheres transexu- } \\
\text { ais acerca do acesso e } \\
\text { tratamento no processo } \\
\text { transexualizador; discu- } \\
\text { tir a visão das mesmas } \\
\text { em relação à patologi- } \\
\text { zação e medicalização. }\end{array}$ & Qualitativa & $\begin{array}{l}\text { A visão patologi- } \\
\text { nizada predomina } \\
\text { na assistência as } \\
\text { mulheres transe- } \\
\text { xuais, fazendo com } \\
\text { que elas vivenciem a } \\
\text { dominação médica e } \\
\text { não participem das } \\
\text { decisões sobre tempo } \\
\text { cirúrgico e demais } \\
\text { elementos respectivos } \\
\text { ao tratamento. }\end{array}$ & $\begin{array}{l}\text { As mulheres transe- } \\
\text { xuais não entendem } \\
\text { a transexualidade } \\
\text { como patologia. } \\
\text { Ainda assim, elas } \\
\text { conseguem perceber } \\
\text { a visão patológica } \\
\text { do profissional como } \\
\text { algo natural. Elas se } \\
\text { submetem a essa } \\
\text { condição, sobretudo } \\
\text { para ter acesso ao } \\
\text { processo transexua- } \\
\text { lizador. }\end{array}$ & $\begin{array}{l}\text { Promoção da } \\
\text { saúde. }\end{array}$ \\
\hline MEDLINE & $\begin{array}{c}\text { Transexualidade } \\
\text { e saúde pública } \\
\text { no Brasil. } \\
2009\end{array}$ & $\begin{array}{l}\text { Discutir a transexu- } \\
\text { alidade no contexto } \\
\text { das políticas de saúde } \\
\text { pública no Brasil. }\end{array}$ & Qualitativa & $\begin{array}{l}\text { As políticas públicas, } \\
\text { embora sigam um pro- } \\
\text { tocolo de assistência, } \\
\text { não tem como única } \\
\text { referência terapêu- } \\
\text { tica a realização do } \\
\text { diagnóstico e a cirurgia } \\
\text { detrangenitalização. }\end{array}$ & $\begin{array}{l}\text { Com uma crítica à } \\
\text { patologização da } \\
\text { transexualidade } \\
\text { na saúde coletiva e } \\
\text { ciências sociais pre- } \\
\text { tende-se destacar } \\
\text { a importância de } \\
\text { compreender a diver- } \\
\text { sidade, e as formas } \\
\text { de subjetivação e de } \\
\text { construção de gênero } \\
\text { na transexualidade. }\end{array}$ & $\begin{array}{l}\text { Promoção da } \\
\text { saúde. }\end{array}$ \\
\hline
\end{tabular}

como um modo de atenção fundamental para homens e mulheres transexuais, isso, porque, quando bem empregada, pode melhorar a sua inclusão na sociedade, favorecer o vínculo, a conquista da autonomia, da autoestima e do autocuidado.

Subsequente, deu-se a apresentação da discussão, que foi construída a partir das informações obtidas dos artigos, organizada em duas unidades sintéticas, intituladas: A transexualidade como um fenômeno novo na saúde e A Promoção da Saúde versus a efetividade da atenção.

\section{DISCUSSÃO}

\section{A transexualidade como um fenô- meno novo na saúde}

A transexualidade é uma terminologia profusa em sua definição, caracterizada pela aspiração de viver e poder ser reconhecido como indivíduo do sexo oposto ao biológico, e pelo anseio de ter seu corpo adequado ao sexo/gênero com o qual se percebe. É um estado sexual reconhecido pela medicina intitulado como transtorno de identidade de gênero (TIG), evidenciado pela sua incompatibilidade entre sexo e gênero, seguido por árduo sofrimento não causado por abnormidade sexual ou disfunções de base orgânica, como acontece com os hermafroditas ${ }^{(7)}$.

É fundamental discutir sobre o corpo, como plano descritível da aparência, porque ele reflete a imagem de um indivíduo.
É nele que a pessoa esboça os aspectos da sua beleza, que exercem sinais e sintomas de todo o processo de saúde, bem como o de adoecimento. As possibilidades de transformações presumem inerência ao processo de saúde e doença na vida das pessoas transexuais ${ }^{(8)}$.

O crescimento significativo da população transexual tem sido evidenciado desde 1997, com isso, esses indivíduos ficaram mais vulneráveis, não só à homofobia, mas psiquiatricamente acarretando vivências e traumas pelo não reconhecimento do gênero ao qual se percebe, sendo excluído no meio em que convive, seja ele familiar, afetivo ou sexual. De maneira que o processo transexualizador se apresenta como um sonho de liberdade, considerado como única 
e viável forma para o reconhecimento de inclusão social ${ }^{(9)}$.

A política pública intitulada de processo transexualizador foi designada com intuito de promoção de aporte hormonal e cirúrgico para correção da incompatibilidade física, dispondo de apoio multidisciplinar durante o processo. $\mathrm{O}$ antagonismo do sexo ao qual se identifica para o biológico contradiz o que a sociedade reconhece como normalidade, o que gera questionamentos e pré-julgamentos. A medicina exerce o domínio através da medicalização a classificando como uma patologia ${ }^{(10)}$.

A transexualidade e/ou transtorno de identidade de gênero é classificado como patologia, permanece no Manual de Diagnóstico Estatístico de Transtornos Mentais (DSM-V) e Classificação Internacional de Doenças (CID-10). Com essa rotulação de transtorno mental, entende-se que necessita de tratamento, logo, a decisão médica sobrepóe-se à vontade da pessoa transexual, incluindo no cenário de saúde ${ }^{(10)}$.

Sendo assim, a CID-10 em sua definição especificou que o desejo de viver e ser reconhecido ao sexo oposto ao do seu nascimento requer tratamento hormonal, psicológico e cirúrgico para que haja uma adequação física e psíquica ${ }^{(10)}$.

O Conselho Federal de Medicina (CFM), em 1997 através da Resolução n. ${ }^{\circ}$ 1842 , permitiu a realização da transgenitalização em usuários transexuais considerando terapêutico. Partindo da premissa que a pessoa transexual é portadora de um desvio psicologicamente irreversível de identidade sexual, negando veemente seu fenótipo e com probabilidade a automutilação e extermínio ${ }^{(9)}$.

Mesmo com a legitimação no Brasil, o acesso a esse serviço segue um protocolo rígido e burocrático, onde os usuários passam a ser acompanhados de maneira criteriosa por psicólogos e psiquiatras por no mínimo dois anos, para que possam concluir o diagnóstico de transtorno de identidade de gênero, condição essa que garantirá a pessoa transexual o acesso ao processo de transgenitalização ${ }^{(9)}$.

A necessidade da medicalização é entendida como meio de mediar confli-
A transexualidade

e/ou transtorno de

identidade de gênero

é classificado como

patologia, permanece

no Manual de

Diagnóstico

Estatístico de

Transtornos

Mentais (DSM-V)

e Classificação

Internacional de

Doenças (CID-10).

Com essa rotulação

de transtorno

mental, entende-

se que necessita de

tratamento, logo,

a decisão médica

sobrepõe-se à vontade

da pessoa transexual,

incluindo no cenário

de saúde. tos onde o indivíduo foge do que é conhecido como heteronormatividade em uma sociedade. Sendo uma ferramenta legal, pautada em normas e concepções científicas e filosóficas tornando a biomedicina soberana às questões sociais que não se enquadram aos rótulos ideais normatizados, o que, consequentemente, acarretam em prejuízo da autonomia da pessoa transexual ${ }^{(10)}$.

Um indivíduo transexual, por mais que não se perceba doente, acaba se submetendo à essa condição patológica para ter acesso ao processo transexualizador, pois quando não se enquadra nas definições pré-concebidas para adequação física, pode vir a perder o direito aos serviços do SUS ${ }^{(10)}$.

Pode-se afirmar que ao associar o diagnóstico de transexualismo à redesignação sexual, tenha viabilizado confrontos distintos à assistência prestada na rede pública de saúde, porém é necessário discutir o quão complexo é estabelecer a condição transexual como uma anomalia, pois entendemos que, no âmbito desses diagnósticos, permitimos o acesso do mesmo ao serviço de saúde e, ao mesmo tempo, restringimos sua autonomia ao seu corpo e vida, trazendo estigma, que dão ênfase a sua exclusão social ${ }^{(9)}$.

O tratamento hormonal é a iniciação do processo de mudanças que ocorrerá no corpo da pessoa transexual, possibilitando a indução de caracteres físicos e sexuais compatíveis ao gênero percebido. É acompanhado pelo endocrinologista e só é interrompido para realização cirúrgica. Nas mulheres transexuais (homens biologicamente que se percebem como mulher), é aplicada a terapia de antiandrogênicos e estrogênio; já para homem transexual (mulheres biologicamente que se percebem como homens) é aplicada a reposição androgênica e testosterona ${ }^{(9)}$.

A cirurgia para transgenitalização em mulheres transexuais dá-se através de desmembramento do pênis, orquiectomia bilateral, retirada parcial do escroto, uretroplastia, construção da neovagina, neoclitoplastia, neovulvoplastia, mamoplastia, e cirurgia de cordas vocais (quan- 
do necessário). Em homens transexuais, a cirurgia ainda é considerada experimental, histerossalpingo, ooforectomia, colpectomia, neofaloplastia, escrotoplastia e mastectomia bilateral ${ }^{(9)}$.

\section{A promoção da saúde versus a efeti- vidade da atenção}

A sociedade ao longo dos anos se viu obrigada a direcionar seus costumes para a questão heteronormativa, mantendo uma postura que, pode parecer nova, entretanto, é conservadora no que diz respeito à pessoa transexual. E isso faz com que muitas dessas pessoas que decidem ser quem são de verdade, encontrem obstáculos no seu dia a dia, como por exemplo, o acesso aos serviços de saúde.

E esse corpo transexual, em transição ou modificado, respaldado no saber técnico e científico da equipe multiprofissional, acaba que por condicionar-se ${ }^{(8)}$. Até porque a dominação entre os profissionais de saúde no atendimento desses usuários é notória no âmbito onde o médico tem a incumbência de sanar o que é visto como loucura, estado de vegetação racional, que, mesmo sem concordar, a pessoa transexual confessa padecer de tal enfermidade para garantir seu acesso ao processo transexualizador, tornando contraditória ao princípio da universalização e integralidade ao acesso à saúde permeado pelo estado ${ }^{(10)}$.

O Ministério da Saúde estabeleceu diretrizes técnicas e éticas para atenção ao processo transexualizador no SUS por meio da portaria GM n. ${ }^{\circ} 1707$, de 18 de agosto de 2008, apesar de importante avanço ainda é precário o acesso ao sistema, principalmente na atenção básica. Já a introdução na carta dos Direitos dos Usuários de Saúde efetivando o direito ao uso do nome social nos serviços de saúde pública, foi uma grande conquista para promoção em saúde dessa população ${ }^{(11)}$.

A assistência a transexuais que buscam o processo transexualizador em sua maioria tem o acesso a esse serviço através de hospitais universitários nas regiões Sul e Sudeste do Brasil, onde têm garantido o atendimento por uma equipe interdisciplinar composta por: cirurgião, psiquia- tra, psicólogo, endocrinologista, assistente social, enfermeiro, anestesista e otorrino, além de uma assessoria jurídica para a mu-

A sociedade ao

longo dos anos se viu

obrigada a direcionar

seus costumes

para a questão

heteronormativa,

mantendo uma

postura que, pode

parecer nova,

entretanto, é

conservadora no que

diz respeito à pessoa

transexual. E isso

faz com que muitas

dessas pessoas que

decidem ser quem

são de verdade,

encontrem obstáculos

no seu dia a dia, como

por exemplo, o acesso

aos serviços de saúde. dança do nome civil após a realização da cirurgia de transgenitalizaçãa ${ }^{(11)}$.

Ainda que o Ministério da Saúde reconheça a orientação dos usuários transexuais, a realidade é que essa população chega aos serviços de saúde, muitas vezes, em condição de extrema vulnerabilidade física, psíquica e social, necessitando não somente do tratamento à saúde física, mas o reconhecimento e inclusão social, ademais alguns desconhecem as informações básicas sobre os seus direitos ${ }^{(9)}$.

É importante discutir os avanços e impasses para o estabelecimento de parâmetros para garantia de direitos, inclusive o da justiça social na perspectiva da equidade e universalidade, que reconheçam e considerem as diferenças entre grupos sociais. O principal desafio para efetivação da assistência é a capacitação profissional da equipe interdisciplinar e modelos de práticas humanizadas, para garantia do atendimento de qualidade despido de discriminação $^{(11)}$.

Para que o SUS funcione de acordo com seus princípios e diretrizes, é preciso ampliar o debate sobre diversidade sexual e de gênero, garantindo a quebra das barreiras geográfica, econômica e cultural entre os serviços e a comunidade que estabelecem a desigualdade de acesso, contribuindo com déficit da promoção em saúde $e^{(7)}$.

$O$ processo de cuidar deve-se iniciar a partir da graduação e permanecer quando esse enfermeiro começa a exercer sua função modificando o ensino conservador, pois quando a educação em saúde é realizada através de aplicações de conhecimentos científicos, o dia a dia no ambiente de trabalho passa a ser mais humanizado e equânime, desobstruindo as barreiras existentes ${ }^{(7)}$.

Com o intuito de estabelecer um cuidado de forma humanizada, o enfermeiro deve ser capaz de entender primeiramente a si mesmo, para depois conseguir olhar para o outro, amplificando esse conhecimento na forma de ação, e tomando consciência dos valores e princípios que norteiam o seu saber-fazer, para o alcance de um olhar holístico, em que a pessoa é 


\section{artigo}

Moreira, S.N.; Paz, F.V.; Azevedo, A.L.; Neves, K.C.; Giesteira, A..,; Azevedo, T.D.P.; Costa, E.C.R.

Atenção à saúde de homens e mulheres transexuais brasileiras: uma evidência de pesquisa

considerada em seu contexto sociocultural e não apenas biológico ${ }^{(12)}$.

Embora o fenômeno da transexualidade não seja um tema tão novo na área da saúde, ele carece de informações, principalmente no que diz respeito à gestação de um homem transexual. Encontrar estudos na língua portuguesa que abordassem diretamente sobre essa temática foi desafiador, haja vista que infelizmente não existem publicações quando o assunto é cuidar desse grupo socialmente vulnerável, deixando a assistência debilitada e o cuidado deficiente.

\section{CONCLUSÃO}

Ficou evidenciado que a atenção à saúde de homens e mulheres transexuais ainda se mostra frágil e ineficiente na atualidade. $\mathrm{E}$ isso acontece porque os profissionais de saúde não se sentem instrumentalizados para atender essa e outras de suas necessidades de forma integral. Há urgência nessa aprendizagem, pela diversidade do assunto e sua subjetivação na construção da identidade de gênero.

E, embora essa clientela se reconheça como pessoas iguais, que não carregam uma doença contagiosa em seu corpo, a forma como os profissionais de saúde olham para eles é nítida. E esse é um olhar de alguém que deseja constantemente que os sonhos dos outros se realizem, portanto, sem preconceitos, cuidadoso, e que traduz todo o compromisso com o processo transexualizador.

Cabe a esses profissionais, ainda que coadjuvantes desse processo, implementar ações de promoção da saúde que sejam, sobretudo: igualitárias, equânimes e humanizadas; sem distinções, inclusivas, acolhedoras, éticas e respeitosas. Colocá-la em prática, no que diz respeito a olhar para a pessoa, não somente para o seu corpo, seu gênero e sua sexualidade, demanda, antes de qualquer obrigatoriedade técnica-científica, a desconstrução de conceitos que, por vezes, potencializam o que por eles é vivido no seu dia a dia.

Com a certeza do inacabado, o que se espera com o desenvolvimento desse estudo é que suscite a curiosidade e o desejo de outros discentes, estimulando-os, sensibilizando-os, e gerando reflexões acerca da atenção à saúde de homens e mulheres que, por vezes, se sentem invisíveis.

\section{REFERÊNCIAS}

1. Ministério da Saúde, Secretaria de Atenção à Saúde Gravidez, parto e nascimento com saúde, qualidade de vida e bem-estar / Ministério da Saúde, Secretaria de Atenção à Saúde, Departamento de Ações Programáticas Estratégicas, Área Técnica de Saúde da Criança e Aleitamento Materno (BR). Área Técnica de Saúde da Mulher [Internet]. - Brasília: Editora do Ministério da Saúde, 2013 [acesso em 20 mar 2019]. 19 p.: il. Disponivel em: http://bvsms.saude.gov.br/bvs/publicacoes/gravidez_parto nascimento_saude_qualidade.pdf ISBN 978-85-334-2033-5.

2. MacDonald T, Noel-Weiss J, West D, Walks M, Biener M, Kibbe A, Myler E. Transmasculine individuals' experiences with lactation, chest feeding, and gender identity: a qualitative study. BMC Pregnancy and Childbirth [Internet]. 2016 [acesso em 20 mar 2019];16:106. Disponivel em: https://bmcpregnancychildbirth. biomedcentral.com/track/pdf/10.1186/s12884-016-0907-y.

3. Jesus JG. Orientações sobre a população transgênero: conceitos e termos / Jaqueline Gomes de Jesus [Internet]. Brasília: Autor, 2012 [acesso em 20 mar 2019]. 24p.: il. Disponivel em: https:// www.sertao.ufg.br/up/16/o/ORIENTA\%C3\%87\%C3\%95ES_POP_ ULA\%C3\%87\%C3\%830_TRANS.pdf?1334065989.

4. Rosa DF, Carvalho MVF, Pereira NR, Rocha NT, Neves VR, Rosa AS. Assistência de Enfermagem à população trans: gêneros na perspectiva da prática profissional. Rev Bras Enferm [Internet]. 2019 [acesso em 28 set 2019];72(Suppl 1):299-306. Disponivel em: http://www.scielo.br/scielo.php?script=sci_arttext\&pid=S0034-71672019000700299\&Ing=pt\&nrm=iso.

5. Ministério da Saúde (BR). Cartilha: Cuidar bem da saúde de cada um. Faz bem para todos. Faz bem para o Brasil [Internet]. Brasília - DF, 2016 [acesso em 20 mar 2019]. Disponível em: portalms.saude.gov.br/images/pdf/2016/.../18/CARTIL-
HA-Equidade-10x15cm.pdf.

6. Soares CB, Hoga LAK, Peduzzi M, Sangleti C, Yonekura T, Silva DRAD. Revisão integrativa: conceitos e métodos utilizados na enfermagem. Rev. esc. enferm. USP. 2014 Apr;48(2):335-345. http://dx.doi.org/10.1590/S0080-6234201400002000020.

7. Ventura M, Schramm FR. Limites e possibilidades do exercício da autonomia nas práticas terapêuticas de modificação corporal e alteração da identidade sexual. Physis. 2009;19(1):65-93. http://dx.doi.org/10.1590/S0103-73312009000100005.

8. Rocon PC, Zamboni J, Sodré F, Rodrigues A, Roseiro MCFB. (Trans)formações corporais: reflexões sobre saúde e beleza. Saúde soc. 2017 Jun;26(2):521-532. http://dx.doi.org/10.1590/ s0104-12902017171907.

9. Aran M, Murta D. Do diagnóstico de transtorno de identidade de gênero às redescrições da experiência da transexualidade: uma reflexão sobre gênero, tecnologia e saúde. Physis. 2009;19(1):15-41. http://dx.doi.org/10.1590/S010373312009000100003.

10. Pinto JJ, Santos RS, Vargens OMC, Araújo, LM. A medicalização e patologização na perspectiva das mulheres transexuais: acessibilidade ou exclusão social. Rev enferm UERJ. 2017; 25:e29009. http://dx.doi.org/10.12957/reuerj.2017.29009.

11. Lionço T. Atenção integral à saúde e diversidade sexual no Processo Transexualizador do SUS: avanços, impasses, desafios. Physis. 2009;19(1):43-63. http://dx.doi.org/10.1590/S010373312009000100004.

12. Aran M, Murta D, Lionço T. Transexualidade e saúde pública no Brasil. Ciênc. saúde coletiva. 2009 ago;14(4):1141-1149. http://dx.doi.org/10.1590/S1413-81232009000400020. 